\title{
CORRECTION
}

\section{Correction to: Real-World Predictors of Major Adverse Cardiovascular Events and Major Adverse Limb Events Among Patients with Chronic Coronary Artery Disease and/or Peripheral Arterial Disease}

Ariel Berger - Alex Simpson - Nicholas J. Leeper - Brian Murphy ·

Beth Nordstrom $\cdot$ Windsor Ting $\cdot$ Qi Zhao $\cdot$ Jeffrey Berger

Published online: January 13, 2020

(C) Springer Healthcare Ltd., part of Springer Nature 2020

Correction to: Adv Ther

https://doi.org/10.1007/s12325-019-01132-z

In the original article, the third author name is incorrect. The correct name is Nicholas J. Leeper.

The original version of this article was revised.

The original article can be found online at https://doi. org/10.1007/s12325-019-01132-z.

A. Berger $(\varangle) \cdot$ B. Murphy $\cdot$ B. Nordstrom

Evidera, Waltham, MA, USA

e-mail: ariel.berger@evidera.com

A. Simpson

Evidera, London, UK

N. J. Leeper

Stanford University Medical School, Stanford, CA,

USA

W. Ting

Mount Sinai Health System, New York, NY, USA

Q. Zhao

Janssen Pharmaceuticals, Raritan, NJ, USA

J. Berger

Center for the Prevention of Cardiovascular Disease,

New York University School of Medicine, New York,

NY, USA 